\title{
ANTIMICROBIAL-RELATED ADVERSE DRUG REACTION IN A TERTIARY CARE HOSPITAL
}

\author{
JINDAL M*, SHARMA RK
}

Department of Pharmacology, Muzaffarnagar Medical College, Muzaffarnagar, Uttar Pradesh, India. Email: drmeenakshijindal@rediffmail.com

Received: 08 April 2017, Revised and Accepted: 10 May 2017

\begin{abstract}
Objective: The objective of the study was to evaluate the adverse drug reaction (ADR) related to commonly used antimicrobials in a tertiary care hospital.

Methods: A prospective spontaneous reporting study involving, active methods (pharmacist actively looking for suspected ADRs) and passive methods (stimulating prescribers to report suspected ADRs) was carried out in all departments of a tertiary care hospital, for 1 year. Patients of all age groups were included in the study. The data for the study were taken from case sheets, investigation reports of patients who had experienced an ADR, personal interviews with reporting persons or clinicians, personal interviews with patient or patient's attendant, past history of medication use, which were generally obtained from, prescriptions from the past, reports of medical and surgical interventions, referral letters, ADR reporting forms. Collected data were then analyze for causality assessment by Naranjo's scale and severity assessment by Hartwig and Siegel's scale.
\end{abstract}

Result: During 1 year of study period, 75 ADRs related to antimicrobial were reported among 1354 patients who were given antibiotic for the treatment. The incidence rate of antibiotic was found to be 5.53\%. The department that reported ADR was medicine (10.16\%), ENT (4.6\%), pediatric $(8.12 \%)$, orthopedics (06.9\%), surgery (06.9\%), chest and tuberculosis $(04.6 \%)$, obstetrics and gynecology $(06.9 \%)$, dentistry $(02.3 \%)$, and skin $(10.16 \%)$. The most common ADRs were related to gastrointestinal tract; dermatological reactions were second in the list of antimicrobial drugs causing ADR. In this study, among antimicrobials, fluoroquinolones, and beta-lactam antibiotics were the most common drugs causing gastrointestinal and dermatological ADRs. There was no unknown ADR reported that may need to be further investigated through active monitoring. All patients recovered from ADRs without any complications. The causality was assessed by Naranjo's scale and it revealed that out of 75 antibiotics related ADR $48(64 \%)$ were possible, 27 (36\%) were probable, 3 (4.00\%) were definate, and 0\% were unlikely. According to the Hartwig and Siegel's scale, most of ADR were mild $45(60 \%)$ and moderate $30(40 \%)$ in nature.

Conclusion: ADRs related to antimicrobials occurs frequently. Among antimicrobials, fluoroquinolones, and beta-lactam antibiotics were the most common drugs causing gastrointestinal and dermatological ADRs. The health-care system can promote the spontaneous reporting of antimicrobial ADR to pharmacovigilance center for ensuring safe drug use and patient care.

Keywords: Adverse drug reaction, Anti microbial, Causality assessment.

(C) 2017 The Authors. Published by Innovare Academic Sciences Pvt Ltd. This is an open access article under the CC BY license (http://creativecommons. org/licenses/by/4. 0/) DOI: http://dx.doi.org/10.22159/ajpcr.2017.v10i8.19380

\section{INRODUCTION}

Drugs are the most common medical interventions, primarily used to relieve sufferings. However, it has been recognized long ago that drug themselves can prove fatal, as the saying rightly goes "Drugs are double edged weapons." Adverse reaction monitoring and reporting are very important in identifying the adverse reaction trends in local population [1]. In simple definition, adverse drug reaction (ADR) has been defined as any noxious, unintended, and undesired effect of a drug which occurs at a dose used in humans for prophylaxis, diagnosis, therapy, or modification of physiological functions [2]. ADRs result in diminished quality of life, increased physician visits, hospitalizations, and even death. There is a need to study ADRs and ADRs reporting to minimize the risk of medicines. Antimicrobial agents are frequently mentioned in studies of ADRs [3] because wide and indiscriminate use of antimicrobial agents has resulted in rise of ADR incidence. According to a study conducted by Novotny et al., the most troublesome classes of drugs contributing to ADRs were antibiotics followed antitumor agents; they are responsible for the recorded adverse effects in approximately $16 \%$ and $15 \%$ of cases, respectively [4] The main aim of this study was to detect and analyze ADRs to antimicrobial drugs in a tertiary care hospital.

\section{METHODS}

A prospective spontaneous reporting study involving, active methods (pharmacist actively looking for suspected ADRs) and passive methods (stimulating prescribers to report suspected ADRs) was carried out in all departments of a tertiary care hospital, for 1 year. Patients of all age groups who developed ADRs of antibiotics were included in the study. The data for the study were taken from case sheets, investigation reports of patients who had experienced an ADR, personal interviews with reporting persons or clinicians, personal interviews with patient or patient's attendant, past history of medication use, which were generally obtained from, prescriptions from the past, reports of medical and surgical interventions, referral letters, ADR reporting forms. They were asked to fill suspected ADR reporting form which elicited information about patient particulars such as name, age, gender, weight, date on which reaction started, date of recovery (if occur), details of reactions, suspected medications (generic and trade name), dose, frequency and route used, indications, other drugs taken concomitantly, and physician remarks (as mentioned in CDSCO's ADR reporting forms). Collected data were then analyze for causality assessment by Naranjo's scale and severity assessment by Hartwig and Siegel's scale.

Severity assessment by modified Hartwig and Siegel severity assessment scale

The severity of the reaction was assessed using the modified Hartwig and Siegel severity assessment scale [5], and the severity is broadly categorized into "mild," "moderate," and "severe" for each ADR. The suspected ADR is "mild" when "an ADR occurs but requires no change in treatment with the suspected drug" or the ADR requires that treatment with the suspected drug be held, discontinued, or otherwise changed. 
No antidote or other treatment requirement was required. No increase in length of stay (LOS). The suspected ADR is "moderate" when "the ADR requires treatment with the suspected drug be held, discontinued, or otherwise changed" and/or "an Antidote or other treatment was required. No increase in LOS" or "any level 3 ADR that increases LOS by at least 1 day," or "the ADR was the reason for the admission." The suspected ADR is "severe" when "Any level 4 ADR that requires intensive medical care or the adverse reaction caused permanent harm to the patient or the adverse reaction either directly or indirectly led to death of the patient."

\section{Causality assessment}

The extent of relationship between suspected ADR and the drug therapy was assessed using the Naranjo's algorithmic scale [6]

\begin{tabular}{ll}
\hline Score & Interpretation of scores \\
\hline Total score $>9$ & $\begin{array}{l}\text { Definite: The reaction, (1) followed a reasonable } \\
\text { temporal sequence after a drug or in which a toxic } \\
\text { drug level had been established in body fluids } \\
\text { or tissues, (2) followed a recognized response } \\
\text { to the suspected drug, and (3) was confirmed } \\
\text { by improvement on withdrawing the drug and } \\
\text { reappeared on re-exposure } \\
\text { Probable: The reaction, (1) followed a reasonable } \\
\text { temporal sequence after a drug, (2) followed } \\
\text { a recognized response to the suspected } \\
\text { drug, (3) was confirmed by withdrawal but } \\
\text { not by exposure to the drug, and (4) could } \\
\text { not be reasonably explained by the known } \\
\text { characteristics of the patient's clinical state } \\
\text { Possible: The reaction, (1) followed a temporal } \\
\text { sequence after a drug, (2) possibly followed a } \\
\text { recognized pattern to the suspected drug, and } \\
\text { (3) could be explained by characteristics of the } \\
\text { patient's disease }\end{array}$ \\
Total score 1-4 score $\leq 0$ & $\begin{array}{l}\text { Doubtful: The reaction was likely related to } \\
\text { factors other than a drug }\end{array}$ \\
\hline
\end{tabular}

\section{RESULTS}

During 1 year of study period, 75 ADRs related to antimicrobial were reported among 1354 patients who were given antibiotic for the treatment. The incidence rate of antibiotic was found to be $5.53 \%$. The department that reported ADR was medicine (10.16\%), ENT (4.6\%), pediatric $(10.16 \%)$, orthopedics $(06.9 \%)$, surgery $(06.9 \%)$, chest and tuberculosis $(04.6 \%)$, obstetrics and gynecology $(06.9 \%)$, dentistry $(8.12 \%)$, and skin $(02.3 \%)$. The most common ADRs were related to gastrointestinal tract; dermatological reactions were second in the list of antimicrobial drugs causing ADR. In the present study, among antimicrobials, fluoroquinolones, and beta-lactam antibiotics were the most common drugs causing gastrointestinal and dermatological ADRs as shown in Table 1. There was no unknown ADR reported that may need to be further investigated through active monitoring. All patients recovered from ADRs without any complications. The causality was assessed by Naranjo's scale and it revealed that out of 75 antibiotic related ADR 48 (64\%) were possible, 27 (36\%) were probable, $3(4.00 \%)$ were definite, and $0 \%$ doubtful as shown in Table 2. According to the Hartwig and Siegel's scale, most of ADR were mild 45 $(60 \%)$ and moderate $30(40 \%)$ in nature.as shown in Table 2.

\section{DISCUSSION}

Antibiotics are used for treatment and prophylaxis of various infectious conditions and are considered as safer drugs when used rationally. However, like all other drugs, they also show some ADRs in various patient conditions. The study tried to find out antimicrobial-related ADR in a large and diverse population. In the studies carried out in Nigerian children antibiotics were the most accounted drug class in ADR occurrence [7]. This study showed an incidence of $5.53 \%$ for antimicrobial-related ADRs which is comparable to other studies Gallelli et al. 2002 [8]; most of the antibiotic ADRs were detected from general medicine and pediatrics departments. This may be due to an increased use of antibiotics in these departments for treatment and prophylaxis of various diseases. The documented antibiotic ADRs are mainly affecting the gold in-tube and skin, and this study also pointed out the same. The study of Benjamin et al. also found the predominance of the gastrointestinal system followed by the skin in ADR occurrence [9]. The study done by Hussain et al. 2010 also showed the predominance of cutaneous manifestations [10]; the beta-lactams and fluoroquinolones were the most used antibiotic class in the hospital, so the reported ADRs were also more in these drug classes. A study conducted by Stavreva et al. also revealed the predominance of beta-lactams [11]. The most of antimicrobial ADR were mild to moderate in nature which was comparable to previous study Jimmy 2008 [12]. The causality assessment of ADRs had been done using the Naranjo scale, in which no reactions were found to be doubtful, and the majority were possible with a less number of probable and definite reactions. Every single ADR case report is important and can make major difference [13] Often the ADR is not recognized and go unreported. The principle limitation of

Table 1: Frequency of ADRs related to antimicrobials

\begin{tabular}{|c|c|c|c|c|c|c|c|c|c|c|c|c|}
\hline \multirow[t]{2}{*}{ Drug } & \multicolumn{12}{|l|}{ n (\%) } \\
\hline & LM & Ab.P & $\mathbf{N}, \mathbf{V}, \mathbf{G}$ & An & TD & Con & Pru & Ras & Jaun & Numb & VD & Total ADR \\
\hline Coamoxclav & $8(57)$ & & & & & & & $6(43)$ & & & & $14(18.6)$ \\
\hline Cefpodoximeproxetil & & & & $4(67)$ & & $2(33)$ & & & & & & $6(8.0)$ \\
\hline Ciprofloxacin & & $3(60)$ & $2(40)$ & & & & & & & & & $5(6.6)$ \\
\hline Ofloxacin & & & & & & $3(75)$ & & $1(25)$ & & & & $4(5.3)$ \\
\hline Norfloxacin & & $1(16)$ & $5(83)$ & & & & & & & & & $6(8.0)$ \\
\hline Cotrimoxazole & $2(40)$ & & & & & & $1(20)$ & $2(40)$ & & & & $5(7.0)$ \\
\hline Azithromycin & $1(50)$ & & & & & & & $1(50)$ & & & & $2(3.0)$ \\
\hline Metronidazole & & & $2(28)$ & & $5(71)$ & & & & & & & 7 (9.8) \\
\hline Nitrofurantoin & & & $3(100)$ & & & & & & & & & $3(4.0)$ \\
\hline Terbinafine & & & & & $2(100)$ & & & & & & & $2(2.6)$ \\
\hline Fluconazole & & & $2(100)$ & & & & & & & & & $2(2.6)$ \\
\hline Amikacin & & & & & & & $2(66)$ & $1(33)$ & & & & $3(4.0)$ \\
\hline Isoniazid & & & & & & & & & & $1(100)$ & & $1(1.3)$ \\
\hline Rifampin & & & & & & & & & $1(100)$ & & & $1(1.3)$ \\
\hline Ethambutol & & & & & & & & & & & $1(100)$ & $1(1.3)$ \\
\hline
\end{tabular}

LM: Loose motion, Ab.P: Abdominal pain, N, V, G: Nausea, Vomiting, Gastritis, An: Anorexia, TD: Taste disturbance, Con: Constipation, Pru: Pruritus, Ras: Rashes,

Jaun: Jaundice, Numb: Numbness, VD: Visual disturbance 
Table 2: Causality and severity assessment

\begin{tabular}{|c|c|c|c|c|}
\hline Drug & Route of administration & ADRs & Causality score & Severity scale \\
\hline \multirow[t]{2}{*}{ Coamoxclav } & Oral & LM Ras & Probable & Moderate L3 mild L1 \\
\hline & & & Possible & \\
\hline \multirow[t]{2}{*}{ Cefixime } & Oral & LM & Probable & Moderate L3 mild L1 \\
\hline & & Ras & Possible & \\
\hline \multirow[t]{2}{*}{ Cefpodoximeproxetil } & Oral & An & Possible & Mild L1 Mild L1 \\
\hline & & Con & Probable & \\
\hline Ciprofloxacin & Oral & Ab.P & Possible & Mild L1 \\
\hline \multirow[t]{2}{*}{ Ofloxacin } & Oral & Con & Possible & Mild L1 \\
\hline & & Ras & Possible & Mild L1 \\
\hline \multirow[t]{2}{*}{ Norfloxacin } & Oral & Ab.P & Possible & Mild L1 \\
\hline & & $\mathrm{N}, \mathrm{V}, \mathrm{G}$ & Probable & Moderate L3 \\
\hline \multirow[t]{3}{*}{ Cotrimoxazole } & Oral & LM & Possible & Mild L1 \\
\hline & & Pru & Possible & Mild L1 \\
\hline & & Ras & Possible & Mild L1 \\
\hline Azithromycin & Oral & L.M & Possible & Mild L1 \\
\hline \multirow[t]{2}{*}{ Metronidazole } & Oral & $\mathrm{N}, \mathrm{V}, \mathrm{G}$ & Probable & Moderate L3 \\
\hline & & TD & Possible & Mild L1 \\
\hline Nitrofurantoin & Oral & $\mathrm{N}, \mathrm{V}, \mathrm{G}$ & Probable & Moderate L3 \\
\hline Terbinafine & Oral & $\mathrm{TD}$ & Possible & Mild L1 \\
\hline Fluconazole & Oral & $\mathrm{N}, \mathrm{V}, \mathrm{G}$ & Possible & Mild L1 \\
\hline \multirow[t]{2}{*}{ Amikacin } & $\mathrm{I} / \mathrm{M}$ & Pru & Probale & Moderate L3 \\
\hline & & Ras & Probale & Moderate L3 \\
\hline Isoniazid & Oral & Numb & Definate & Moderate L3 \\
\hline Rifampin & Oral & Jaun & Definate & Moderate L3 \\
\hline Pyrazinamide & Oral & Jaun & Probable & Moderate L3 \\
\hline Ethambutol & Oral & VD & Definate & Moderate L3 \\
\hline
\end{tabular}

LM: Loose motion, Ab.P: Abdominal pain, N, V, G: Nausea, Vomiting, Gastrities, An: Anorexia, TD: Taste disturbance, Con: Constipation, Pru: Pruritus, Ras: Rashes, Jaun: Jaundice, Numb: Numbness, VD: Visual disturbance, L1: The ADR require no change in the treatment with the suspected drug, L3: The ADR requires that the suspected drug is withheld, discontinued otherwise changed and/or an antidote or other treatment is required. There is no increase in length of stay

ADR detection is lack of awareness of, what constitutes an ADR. Most of the ADRs are bought to medical attention by subjective reports and patients complaints [14].

\section{CONCLUSION}

Antibiotics are the most widely prescribed drug so it require more ADR monitoring. Hence, implementation of the spontaneous reporting of ADRs to antibiotics should be encouraged and periodic reporting to regional pharmacovigilance centers should be done to ensure patient safety.

\section{REFERENCES}

1. Abimanyu P, Nagari BG. Safety of medicines. Pharm Times 2003;35:19-21.

2. Sudershan V, Siddiqua S, Aruna D, Manmohan RS, Ramesh S, Yasmeen N. Cutaneous adverse drug reactions in a tertiary care hospital. Pharm Lett 2011;3(6):210-7.

3. Moore N, Lecointre D, Noblet C, Mabille M. Frequency and cost of serious adverse drug reactions in a department of general medicine. $\mathrm{Br}$ J Clin Pharmacol 1998;45:301-8.

4. Novotny J, Novotny M. Adverse drug reactions to antibiotics and major antibiotic drug interactions. Gen Physiol Biophys 1999;18:126-39.

5. Hartwig SC, Siegel J, Schneider PJ. Preventability and severity assessment in reporting adverse drug reactions. Am J Hosp Pharm 1992;49:2229-32.
6. Naranjo CA, Busto U, Sellers EM, Sandor P, Ruiz I, Roberts EA, et al. A method for estimating the probability of adverse drug reactions. Clin Pharmacol Ther 1981;30:239-45.

7. Priyadharsini R, Surendiran A, Adithan C, Sreenivasan S, Kumar SF. A study on adverse drug reactions in paediatric patients. J Pharmacol Pharmacother 2011;2(4):277-80.

8. Gallelli L, Ferreri G, Colosimo M, Pirritano D, Guadagnino L, Pelaia $\mathrm{G}$, et al. Adverse drug reactions to antibiotics observed in two pulmonology divisions of catanzaro, Italy: A six-year retrospective study. Pharmacol Res 2002;46:395-400.

9. Benjamin H, Jean-Louis M, Lapeyre-Mestre M. Adverse drug reactions and off-label drug use in paediatric outpatients. Br J Clin Pharmacol 2002:54:665-70.

10. Hussain MM, Girhepunje K, Pal R, Siddiqua SS. Incidence of adverse drug reactions in a tertiary care hospital: A systematic review and metaanalysis of prospective studies. Pharm Lett 2010;2(3):358-68.

11. Stavreva G, Pendicheva D, Pandurska A, Marev R. Detection of adverse drug reactions to antimicrobial drugs in hospitalized patients. Trakia J Sci 2008;6(1):7-9.

12. Jimmy J, Padma GM, Beena J.Adverse drug reactions to fluoroquinolone antibiotics - Analysis of reports received in a tertiary care hospital. Int $\mathrm{J}$ Risk Saf Med 2008;20:169-80.

13. Iffat W, Shakeel S, Naseem S, Iman S, Khan M. Attitudinal survey to assess medical and dental students belief of ADR reporting in Pakistan. Int J Pharm Pharm Sci 2014;6(5):279-83.

14. Kathiria MJ, Sattigeri MB, Parth MD, Patel PS. A study of adverse drug reactions in patients admitted to intensive care unit of a tertiary care teaching rural hospital. Int J Pharm Pharm Sci 2013;5(1):160-3. 